\title{
Appropriateness of decisions as a moderator of the psychology of voice
}

\author{
KEES VAN DEN BOS ${ }^{1 *}$ AND NIENKE SPRUIJT ${ }^{2}$ \\ ${ }^{1}$ Department of Social Psychology, \\ Free University Amsterdam, The Netherlands \\ ${ }^{2}$ Department of Social and Organizational \\ Psychology, Leiden University, The Netherlands
}

\begin{abstract}
This paper focuses on the psychology of the voice effect (the effect that people show more positive reactions when they are allowed an opportunity to voice their opinion in the decision-making process than when they are denied such an opportunity). It is argued that it is important to ask about what decisions people are allowed voice. More specifically, results of two experiments suggest that when participation in decision making is appropriate (i.e. voice is allowed about decisions that are relatively important to participants) the voice effect is found: People's procedural judgements and other reactions are more positive following voice as opposed to no-voice procedures. However, when participation in decision making is inappropriate (i.e. voice is allowed about decisions that are unimportant to participants) no effect or even a reversal of the voice effect is found. These people do not react differently or even react more negatively following voice as opposed to no-voice procedures. It is concluded that these results further our insights into the psychology of procedural justice in general and voice in particular. Copyright (C) 2002 John Wiley \& Sons, Ltd.
\end{abstract}

The norms and values of fairness and justice constitute a fundamental feature of human life. Not surprisingly, therefore, the issue of justice has received considerable attention from social psychologists (Lind \& Tyler, 1988). One of the most frequently replicated findings in social psychology has been the discovery that people show more positive reactions when they are allowed an opportunity to voice their opinion in the decision-making process than when they are denied such an opportunity. These voice effects have been found on perceptions of procedural fairness, attitudes towards supervisors, relational judgements about authorities, task performance, and measures of affect, such as anger against officials (Lind, Kanfer, \& Earley, 1990; Lind \& Tyler, 1988; Tyler, 1987; Tyler \& Lind, 1992). Furthermore, the effects have been found in both Western and non-Western societies and in laboratory experiments as well as in studies conducted in natural settings (Lind \& Tyler, 1988; Tyler \& Lind, 1992).

*Correspondence to: Kees van den Bos, Department of Social Psychology, Free University Amsterdam, Van der Boechorststraat 1, 1081 BT Amsterdam, The Netherlands. Tel: +31 20444 8964. Fax: +31 20444 8921. E-mail: k.van.den.bos@psy.vu.nl

Contract grant sponsor: Royal Netherlands Academy of Arts and Sciences

Copyright (C) 2002 John Wiley \& Sons, Ltd.

Received 19 September 2000

Accepted 19 March 2001 
Thus, numerous studies show the robustness of the effects of getting voice versus no voice. Indeed, in their comprehensive analysis of the social psychology of procedural justice, Lind and Tyler (1988) concluded that the great bulk of the studies that have looked for these effects have found them. This robustness has led to a strong tendency in the social psychology of procedural justice to equate voice procedures with just procedures and no-voice procedures with unjust procedures (Van den Bos, Vermunt \& Wilke, 1996). The primary aim of the present paper is to try to further the social psychology of voice, with particular attention to the robustness of the concept.

One of the reasons why this is important is the fact that voice plays an important role in modern societies. For example, in the country we live in (The Netherlands), politicians frequently organize socalled participation nights ('inspraak-avonden'), in which civilians are asked to voice their opinions about political decisions that have to be made. However, relatively few civilians attend these participation nights. In newspapers and other media it has been discussed why this is the case. One of the propositions that has been made is that politicians are appointed to make political decisions, and that therefore (some) civilians find it inappropriate to voice their opinions about these decisions. In the current paper, we would like to elaborate on this and provide empirical evidence for some elements of this line of reasoning.

To achieve this purpose, we will integrate the social psychological domain of voice with the organizational field of participation in decision making (PDM). We do this because, although the concepts of voice and PDM seem to be highly related, the two concepts tend to be studied in separate research domains (social psychology and organizational studies, respectively). We would like to explicitly argue here that the two concepts share many similarities. After all, it may be argued that having a voice is just one form of participation in decision making (Folger, 1977; Earley \& Lind, 1987). Furthermore, like voice, people judge PDM to be more fair and PDM increases satisfaction, acceptance, and loyalty with organizations (Straus, 1992; Locke \& Schweiger, 1979). We propose here that, because of these similarities, insights from the PDM domain could lead to a better understanding of the social psychology of voice. Below we will discuss PDM studies that are relevant for the present purposes. We will note some important methodological problems of these studies. After this, we will discuss the purposes of the current research.

\section{PARTICIPATION IN DECISION MAKING}

In their conceptual framework of PDM, Dachler and Wilpert (1978) argued that the democratic and socialistic theories as well as the human growth and development and the efficiency and productivity orientations argue in favour of restricting PDM to situations in which decisions are in line with the current abilities, needs, or expectations of the people involved. In other words, PDM theories imply that an important aspect of PDM in real-life situations is whether or not people are allowed participation in decisions about which they judge it to be appropriate to receive participation. We argue here that these theoretical suggestions are important because - in contrast to the concept of participation nights - they suggest that participation in decision making is not a panacea, always positively affecting people's reactions. The PDM literature rather suggests that it is important to explicitly ask ourselves whether input in decisions is appropriate or inappropriate.

Some PDM studies are related to this proposition. For example, research by the DIO International Research Team (1983) made a distinction between strategic decisions which are of direct importance to the survival and continuity of the organization, and tactical decisions which are directed towards control systems such as personnel policy and adequate work performance. Strategic decisions generally take a relatively long time, are made relatively infrequent, and are typically initiated and dominated by the top 
of the organization. Tactical decisions take less time, occur more often, and take place at lower levels within the organization. Research findings of the DIO team showed a positive effect of participation in tactical decision making: Participation in tactical decisions increased employees' satisfaction with their outcome. With regard to strategic decisions, however, such positive relationships did not exist. In fact, the results suggested a negative relationship between employees' performance and participation in strategic decision making. These are potentially important results. However, the DIO conclusions were based on correlational data, raising important questions of causality. Fortunately, experimental studies on the issues the DIO team explored have been conducted as well.

Sagie, Elizur, and Koslowsky (1995) conducted an experiment in which participants were allowed participation or no participation (referred to as 'direction') in both 'strategic' and 'tactical' decision making (see also Sagie et al., 1989). The results showed more positive reactions following participation as opposed to no participation in tactical decisions whereas more negative reactions were found following participation as opposed to no participation in strategical decisions. It should be noted here, however, that the manipulations of the Sagie et al. $(1989,1995)$ experiments had serious drawbacks. Most important for the present purposes, instead of crossing the two types of decisions with the two sorts of decision-making procedures, all participants in the Sagie et al. (1995) experiment experienced both decisions in the same order. All participants first reacted to the strategical decision and then to the tactical decision. Because of this order problem it is difficult to confidently interpret the results of the Sagie et al. studies.

Thus, the above-discussed PDM results are potentially interesting because they suggest that participation in decision making is not a panacea, always positively affecting people's reactions. The PDM data suggest that it is important to explicitly ask ourselves about what decision participation is allowed. Unfortunately, however, we have seen that methodological aspects of the studies make it hard to definitely conclude that this suggestion is warranted.

\section{THE CURRENT RESEARCH}

In the present paper, we would like to follow up the suggestive findings of the above mentioned PDM studies that participation in 'tactical' and 'strategical' decisions may have different effects on people's reactions. That is, we would like to focus on appropriateness of input in decisions that, we propose here, may have caused the effects that were reported in the PDM studies and that may also affect people's reactions to voice and no-voice procedures.

We argue here that people may find it appropriate to receive voice about many decisions that have to be made. As an example, consider the situation in which a cleaner at a university is allowed an opportunity to voice his opinion about how many floors he should clean in one day. We propose that the cleaner would value an opportunity to voice his opinion about such a decision that is relevant and important for his working situation and about which he probably has meaningful things to say. We will refer to these kinds of decisions - about which it is appropriate to receive voice - as appropriate decisions.

However, there also may be decisions about which people may feel that they have not very meaningful things to say. As an example may serve the situation in which the cleaner of the university is allowed an opportunity to voice his opinion about the university's research program. The cleaner's reactions may not be strongly affected by this opportunity to voice his opinion about this decision that is far less relevant and important for his own work and about which he probably does not have strong opinions and many things to say. We will label these kinds of decisions - about which being allowed a voice may be inappropriate - as inappropriate decisions. 
Thus, we would like to argue for making a distinction between situations in which voice is allowed about appropriate decisions and circumstances in which people are asked to voice their opinions about decisions that are inappropriate for them. One of the reasons why this is important, we argue here, is that this distinction typically is not made in both the scientific literature on voice and in everyday life (such as in the decision process of whether to organize another participation night), whereas we would like to show here that it can have strong effects on people's reactions to voice and no-voice procedures.

\section{EXPERIMENT 1}

In the first experiment we report here, we vary whether participants are or are not allowed voice about an appropriate or an inappropriate decision. The appropriate decision involves the interest of a participant and is suitable for his or her role. The decision issue we used in our experiment was the number of tasks a participant had to complete in a 10-minute work round. In correspondence with the experiments by Lind et al. (1990) and Van den Bos et al. (1996), in Experiment 1 it was very appropriate to ask a participant to give his or her opinion about this issue. Because the participant already had practiced with the tasks, he or she could estimate the number of tasks he or she could complete. The inappropriate decision, however, did not involve the interests of the participant and did not belong to his or her responsibility. The decision we used was about the number of tasks a participant had to complete in 10 minutes in order to be able to conduct a good psychological study. This is a decision the experimenter has to make, he or she probably is informed about the purposes of the experiment, and this decision belongs to the responsibility of the experimenter. It is inappropriate to ask a participant how to conduct a good psychological study. After all, participants are not required to know how to conduct good psychological research.

On the basis of the above-presented line of reasoning, we expected an interaction effect between type of decision and procedure. We predicted that participants who received an opportunity to voice their opinion about an appropriate decision would react more positively than participants who did not receive an opportunity to voice their opinion (Hypothesis 1). We further hypothesized that reactions of participants who were confronted with an inappropriate decision would differ less as a function of whether they were or were not allowed an opportunity to voice their opinion (Hypothesis 2a) or even would react less positively when they received a voice than when they did not receive such an opportunity (Hypothesis $2 \mathrm{~b}$ ). We focused on two procedural justice judgements that are typically measured in studies on the voice effect: We asked participants how fair and just they considered their procedure. Furthermore, because it is important to measure affective elements in people's responses (cf. Tyler \& Smith, 1998; Vermunt, Wit, Van den Bos, \& Lind, 1996), and following Van den Bos (2001), we also asked participants how furious they felt following the procedure.

\section{Method}

\section{Participants and Design}

Eighty-eight students ( 32 men and 56 women) at Leiden University participated in the experiment and were paid 10 Dutch guilders (which equals 4.54 Euro) for their participation. Participants were randomly assigned to one of the conditions of the 2 (procedure: voice versus no voice) $\times 2$ (decision type: appropriate versus inappropriate) factorial design. A minimum of 21 and a maximum of 23 participants took part in each of the four conditions. 


\section{Experimental Procedure}

Participants were invited to the laboratory to participate in a study on how people perform tasks. Upon arrival at the laboratory, participants were led to separate cubicles, each containing a computer. The computers were used to present the stimulus information and to collect the data pertaining to the manipulation checks and the dependent variables. After a short explanation how to use the computer, the experimental procedure was described. Participants were told, by means of the computer network, that they would perform a practice round of 2 minutes and a work round of 10 minutes. Participants then received an explanation about the tasks they would perform. Figures were presented on the upperright side of the computer screen. Each figure consisted of 36 squares and each square showed one of eight different patterns. On the upper-left side of the screen one of the eight patterns was presented, and participants had to count the number of squares with this pattern in the figure on the right side of the screen. When participants had indicated the correct number of patterns in the figure, another figure with another pattern was presented on the screen (cf. Van den Bos et al., 1996). In both the practice round and the work round, the number of tasks that the participant had completed (i.e. the number of figures that the participant had counted) in the present round was presented on the lowerright side of the screen. On the lower-left side of the screen the time remaining in the present round was shown.

After the practice round, participants were informed about a decision the experimenter had to make. In the appropriate decision condition, participants were told that the experimenter had to decide about the number of tasks a participant had to complete in the 10-minute work round (cf. Lind et al., 1990; Van den Bos et al., 1996). In the inappropriate decision condition, it was communicated to the participants that the experimenter had to decide about the number of tasks a participant had to complete in 10 minutes in order to be able to conduct a good psychological study. After this, participants in the voice condition were informed that they were allowed an opportunity to voice their opinion about the decision. Participants in the no-voice condition were informed that they were not allowed an opportunity to voice their opinion about the decision.

The participants then responded to questions pertaining to the manipulation checks and the dependent variables. All ratings were made on 7-point Likert-type scales. Participants were asked how fair $(1=$ very unfair, $7=$ very fair $)$ and just $(1=$ very unjust, $7=$ very just $)$ they considered the decision-making process ${ }^{1}$ and to what extent they were furious following the process $(1=$ very weak, $7=$ very strong). To check whether participants had understood the information about the type of decision we gave them, participants were asked to indicate to what extent they agreed with the statement 'The decision the experimenter had to make was about the number of tasks a participant had to complete in 10 minutes' ( $1=$ strongly disagree, $7=$ strongly agree $)$, and to what extent they agreed with the statement 'The decision the experimenter had to make was about the number of tasks a participant had to complete in 10 minutes in order to be able to conduct a good psychological study' $(1=$ strongly disagree, $7=$ strongly agree). To check whether the procedure had been perceived as intended, participants were asked to what extent they agreed with the statement that they had been given an opportunity to voice their opinion $(1=$ strongly disagree, $7=$ strongly agree $)$ and to what extent they agreed with the statement that they had not been given an opportunity to voice their opinion ( $1=$ strongly disagree, $7=$ strongly agree). To further validate the manipulation of procedure (cf. Tyler, 1987), participants were asked how much influence they thought they had on the outcome of the decision-making process $(1=$ very weak, $7=$ very strong $)$. After they had answered these questions, participants were told that the work round was cancelled. After this, they were thoroughly debriefed,

\footnotetext{
${ }^{1}$ Participants' procedural fairness and justice judgements in Experiment 1 were not highly correlated, $r=0.49$, and it was therefore more appropriate to treat these two judgements separately in the data analyses to be reported below.
} 
were asked not to inform other potential participants about the experiment, and were paid and thanked for their participation.

\section{Results}

\section{Manipulation Checks}

A $2 \times 2$ multivariate analysis of variance (MANOVA) on the two manipulation checks of decision type (appropriate and inappropriate) yielded only a main effect of decision type at both the multivariate level and the univariate levels: multivariate $F(2,83)=47.17, p<0.001$; for the appropriate decision check, $F(1,84)=84.88, p<0.001$; for the inappropriate decision check, $F(1,84)=36.24, p<0.001$. This revealed that participants who were informed about the appropriate decision agreed more with the statement about the appropriate decision $(M=5.8 ; S D=1.4)$ than participants who were informed about the inappropriate decision $(M=2.7 ; S D=1.9)$, and that participants who were informed about the inappropriate decision agreed more with the statement about the inappropriate decision $(M=5.9$; $S D=1.3)$ than participants who were informed about the appropriate decision $(M=3.4 ; S D=2.0)$. This suggests that the decision-type manipulation was successfully operationalized.

A $2 \times 2$ MANOVA on the two manipulation checks of procedure (voice and no voice) yielded only a main effect of procedure at both the multivariate level and the univariate levels: multivariate $F(2$, $83)=93.64, p<0.001$; for the voice check, $F(1,84)=122.19, p<0.001$; for the no-voice check, $F(1$, $84)=154.94, p<0.001$. These findings show that participants in the voice condition agreed more with the statement that they had been given an opportunity to voice their opinion $(M=5.9 ; S D=1.4)$ than participants in the no-voice condition $(M=2.1 ; S D=1.7)$, and that participants in the no-voice condition agreed more with the statement that they were not given an opportunity to voice their opinion $(M=5.9 ; S D=1.5)$ than participants in the voice condition $(M=2.0 ; S D=1.4)$. It can be concluded that the procedure manipulation was successfully operationalized.

A $2 \times 2$ analysis of variance (ANOVA) on participants' answers whether they thought they affected the outcome of the decision-making process yielded only a main effect of procedure, $F(1,84)=11.59$, $p<0.01$. As expected, participants who had received an opportunity to voice their opinion thought they had more influence on the outcome $(M=4.2 ; S D=1.6)$ than participants who had not received such an opportunity $(M=2.9 ; S D=1.9)$. This yields corroborative evidence that the manipulation of procedure was induced as intended.

\section{Dependent Variables}

The means and standard deviations of the dependent variables of Experiment 1 are displayed in Table 1. To analyse the data we conducted a $2 \times 2$ MANOVA on the three dependent variables (procedural fairness, procedural justice, and furiousness). This MANOVA yielded main effects of procedure at the multivariate level and at two univariate levels (for fairness and justice): multivariate $F(3,82)=6.25$, $p<0.01$; for fairness perceptions, $F(1,84)=8.84, p<0.01$; for justice perceptions, $F(1,84)=15.47$, $p<0.001$. More important, the predicted interaction effects were found at the multivariate level and all univariate levels: multivariate $F(3,82)=8.17, p<0.001$; for procedural fairness perceptions, $F(1,84)=10.78, p<0.01$; for perceived procedural justice, $F(1,84)=18.11, p<0.001$; for feelings of furiousness, $F(1,84)=6.80, p<0.02$.

The results show that, as predicted by Hypothesis 1, participants in the appropriate decision condition judged the procedure to be more fair when they were given an opportunity to voice their 
Table 1. Means and standard deviations of the dependent variables as a function of decision type and procedure (Experiment 1)

\begin{tabular}{llcc}
\hline & & \multicolumn{2}{c}{ Decision } \\
\cline { 3 - 4 } Dependent variable & Procedure & Appropriate & Inappropriate \\
\hline Procedural fairness & Voice & $\mathbf{5 . 1}(1.5)$ & $\mathbf{4 . 9}(1.3)$ \\
& No voice & $\mathbf{3 . 4}(1.2)$ & $\mathbf{5 . 0}(1.2)$ \\
Procedural justice & Voice & $\mathbf{5 . 7}(1.1)$ & $\mathbf{5 . 0}(1.4)$ \\
Furiousness & No voice & $\mathbf{3 . 5}(1.3)$ & $\mathbf{5 . 1}(1.4)$ \\
& Voice & $\mathbf{1 . 4}(1.1)$ & $\mathbf{1 . 7}(1.4)$ \\
& No voice & $\mathbf{2 . 1}(1.4)$ & $\mathbf{1 . 1}(0.3)$ \\
\hline
\end{tabular}

Note: Entries in bold are means on 7-point Likert-type scales with higher values indicating more positive ratings of the dependent variable in question, and entries within parentheses are standard deviations.

opinion than when they were not given such an opportunity, $t(41)=4.13, p<0.001$. In accordance with Hypothesis 2a, procedural fairness judgements in the inappropriate decision condition did not differ as a function of procedure, $t(43)=-0.24$, n.s.

In accordance with Hypothesis 1, it was found that participants in the appropriate decision condition judged the procedure to be more just when they were given an opportunity to voice their opinion than when they were not given such an opportunity, $t(41)=5.83, p<0.001$. As predicted by Hypothesis $2 \mathrm{a}$, the results did not show a difference in procedural justice judgements between the voice and the no-voice conditions in the inappropriate decision condition, $t(43)=-0.23$, n.s.

The furiousness findings showed further evidence for our predictions. As predicted, participants in the appropriate decision condition were more furious when they were not given an opportunity to voice their opinion than when they were given such an opportunity, $t(41)=-1.70, p<0.05$. Moreover, supportive evidence was found for Hypothesis 2b. As predicted by this hypothesis, participants in the inappropriate decision condition were more furious when they were given an opportunity to voice their opinion than when they were not, $t(43)=2.04, p<0.05$ (one-tailed).

\section{Discussion}

The findings of Experiment 1 provide supportive evidence for our argument that appropriateness of decisions affects how people react to voice and no-voice procedures. According to our knowledge, research on the voice effect thus far failed to pay attention to appropriateness of decisions. Research has been limited to situations where people received voice or no voice about appropriate decisions (see e.g. Lind et al., 1990; Van den Bos et al., 1996; for an overview, see Lind \& Tyler, 1988). In these situations, voice positively affects people's procedural judgements and other reactions. In Experiment 1, we found evidence for this: Participants judged the procedure to be more fair and just and they described themselves as less furious when they were allowed rather than denied voice about an appropriate decision. Thus, when people are confronted with an appropriate decision, the voice effect appears.

We also argued, however, that when faced with an inappropriate decision, people's reactions will not differ much or even will be less positive when they are given an opportunity to voice their opinion as opposed to when they are not given such an opportunity. We expected that in this situation the voice effect would only weakly appear or even would reverse. In accordance with our line of reasoning, Experiment 1 shows that when participants are confronted with an inappropriate decision, procedural fairness and justice judgements did not statistically differ as a function of procedure. More specifically, 
when people were faced with an inappropriate decision, procedure judgements were not significantly more negative in the no-voice condition than in the voice condition. Furthermore, participants' emotions of furiousness even revealed a reversal of the voice effect. That is, participants were less furious when they were not allowed an opportunity to voice their opinion about an inappropriate decision than when they were allowed such an opportunity. On the basis of the findings of Experiment 1 , we conclude that perceptions of procedural fairness and justice and experienced emotions (such as furiousness) depend in part on the type of decision about which voice is or is not allowed. These findings suggest that appropriateness of decisions is a new moderator of the voice effect.

\section{EXPERIMENT 2}

Before we draw strong conclusions on the basis of the findings of Experiment 1, however, it is important to replicate them. Conducting a second experiment is also important because in Experiment 1 the manipulation of decision type was successful in yielding some well-specified effects on people's reactions, but it might be argued that there are several psychological mechanisms that could explain the findings observed. In Experiment 2, we focus on a significant psychological mechanism, both from the perspective of instrumental and relational models of procedural justice models (see Thibaut $\&$ Walker, 1975; Tyler \& Lind, 1992). According to these models, a crucial distinction is whether people are confronted with decisions that are important or unimportant for themselves (cf. Cropanzano \& Ambrose, 'There is no such thing as procedural justice', unpublished manuscript, 1997; Huo, Presentation at the Annual Meeting of the American Psychological Society, Denver, CO, June 1999). We argue here that in Experiment 1 the inappropriate decision was relatively unimportant for participants themselves and that the appropriate decision was relatively more important for participants. To assess the validity of this assumption, we manipulate more directly in Experiment 2 that participants either receive or are denied an opportunity to voice their opinions about a decision that is either unimportant or relatively more important to them. Findings by Van den Bos and Lind ('The psychology of own versus others' treatment: Self-oriented and other-oriented effects on perceptions of procedural justice', Personality and Social Psychology Bulletin, in press, Experiment 1) suggest that people find decisions that are related to themselves to be more important than decisions that apply to another person. In Experiment 2, therefore, we vary that participants are or are not allowed a voice about a decision that concerns either themselves or another participant. That is, the decision about which participants are or are not allowed voice involves the number of tasks that either participants themselves or another participant than participants themselves will have to complete in a subsequent work round.

In Experiment 2, we assessed the same two procedural justice judgements that we measured in Experiment 1 (perceived procedural justice and fairness), but, by improving our measurement methods, we tried to come up with variables that were more strongly associated than these variables were in Experiment 1 (see footnote 1). We again measured participants' affective reactions, but because it is important to measure (1) dependent variables that have been used in previous fairness experiments (see e.g. Van den Bos, 2001; Van den Bos, Bruins, Wilke, \& Dronkert, 1999) and (2) positive as well as negative affect (Watson, Clark, \& Tellegen, 1988) - this time we not only solicited how furious participants felt about the procedure, but also how happy, pleased, and satisfied they were with the procedure (cf. Van den Bos, 2001; Van den Bos et al., 1999). Because it is important to assess how people react to authorities (Tyler \& Lind, 1992), we also measured theoretically established relational evaluations of the experimenter: We asked participants to what extent they respected and trusted the experimenter and to what extent the experimenter had treated them politely and respectfully. 


\section{Method}

\section{Participants and Design}

One hundred and twenty-two students (56 men and 66 women) at Leiden University participated in the experiment and were paid 7.50 Dutch guilders for their participation. Participants were randomly assigned to one of the conditions of the 2 (procedure: voice versus no voice) $\times 2$ (decision type: appropriate versus inappropriate) factorial design. A minimum of 29 and a maximum of 32 participants took part in each of the four conditions.

\section{Experimental Procedure}

The participants were invited to the laboratory to participate in a study on how people perform tasks. Upon arrival at the laboratory, participants were led to separate cubicles, each containing a computer. The computers were used to present the stimulus information and to collect the data pertaining to the manipulation checks and the dependent variables. It was communicated to the participants that they participated together with another, comparable participant. After a short explanation how to use the computer, the experimental procedure was described. Participants were told, by means of the computer network, that both they and the other participant would perform a practice round of two minutes, a first work round of 10 minutes, and a second work round of 20 minutes.

Participants then received an explanation about their task and were given an opportunity to practice their task for two minutes. Participants' task in the decision about self condition ${ }^{2}$ was the figurecounting task we used in Experiment 1. Participants' task in the decision about the other participant condition was a dot-counting task in which participants had to push the return button each time a small dot appeared on the computer screen. In all decision type conditions and in all practice and work rounds, the number of tasks that the participant had completed in the present round and the number of errors participants had made in the present round was presented on the lower-right side of the screen. On the lower-left side of the screen the time remaining in the present round was shown.

After this, participants received an explanation about the other participant's task and were given an opportunity to practice other's task for 2 minutes. Other participant's task in the decision about self condition was the dot-counting task, and other's task in the decision about other participant condition was the figure-counting task. Participants then performed the first work round, consisting of 10 minutes, after which they were told how many tasks they had completed in the work round and that the other participant had completed 111 tasks. $^{3}$ After this, participants in the decision about self condition were informed that the experimenter had to decide about the number of tasks they had to complete in the second work round. Participants in the decision about the other participant condition were told that the experimenter had to decide about the number of tasks the other participant had to complete in the second work round. Participants in the voice condition then were informed that they were allowed an opportunity to voice their opinion about the decision. Participants in the no-voice condition were informed that they were not allowed an opportunity to voice their opinion about the decision.

\footnotetext{
${ }^{2}$ To ensure that in both decision type conditions (self versus other) participants would be focusing on a decision that had to do with the same task, we varied what tasks were presented as participants' task and other participant's task. Participants practiced both tasks, pilot testing revealed that both the figure counting and the dot counting tasks were judged to be equally difficult and interesting, and debriefing interviews indicated that we were successful in presenting participants with comparable yet different tasks.

${ }^{3}$ Pilot testing revealed that participants generally completed 111 tasks, and we therefore communicated to the participants that the other participant had completed this number of tasks. Data to be presented confirmed that participants thought their own and other participant's performance in the first work round was comparable.
} 
The participants then responded to questions pertaining to the manipulation checks and the dependent variables. All ratings were made on 7-point Likert-type scales. Participants' procedural justice judgements were assessed by asking them how fair $(1=$ very unfair, $7=$ very fair $)$ and just $(1=$ very unjust, $7=$ very just $)$ they considered the decision-making process. Because in this experiment these two judgements were highly correlated, $r=0.91$, we averaged participants' answers to form a procedural justice judgements scale $(\alpha=0.95)$. Participants' affective procedural perceptions were measured by asking them how happy $(1=$ very unhappy, $7=$ very happy $)$, pleased $(1=$ very displeased, $7=$ very pleased $)$, satisfied $(1=$ very dissatisfied, $7=$ very satisfied $)$, and furious $(1=$ not at all furious, $7=$ very furious) they were about the decision-making processes. After recoding participants' furiousness perceptions, these four dependent variables were averaged to form a procedural affect scale $(\alpha=0.83)$. Relational judgements were solicited by asking participants to what extent they respected the experimenter $(1=$ very weak, $7=$ very strong $)$, trusted the experimenter $(1=$ very weak, $7=$ very strong $)$, the experimenter had treated them politely $(1=$ very weak, $7=$ very strong), and the experimenter had treated them respectfully $(1=$ very weak, $7=$ very strong $)$. These four perceptions were averaged to form a relational judgements scale $(\alpha=0.87)$.

By means of the manipulation of decision type we tried to establish that participants were confronted with a relatively important or unimportant decision. As check on the decision type manipulation, therefore, we asked participants to what extent they judged the decision about which they had or had not received a voice to be important or unimportant $(1=$ very unimportant, $7=$ very important). To check whether the procedure had been perceived as intended, participants were asked to what extent they agreed with the statement that they had been given an opportunity to voice their opinion $(1=$ strongly disagree, $7=$ strongly agree $)$ and to what extent they agreed with the statement that they had not been given an opportunity to voice their opinion $(1=$ strongly disagree, $7=$ strongly agree). To further validate the manipulation of procedure (cf. Tyler, 1987), participants were asked to what extent the experimenter had paid attention to their opinions $(1=$ very weak, $7=$ very strong $)$. By means of our experimental situation we tried to establish that participants in both decision type conditions were dealing with comparable situations. Because it was important that participants were not downgrading the other participant's task performance, we assessed participants thoughts about their own task performance relative to the other participant's task performance by asking them how hard they themselves had worked in the first work round $(1=$ not hard at all, $7=$ very hard $)$ and how hard the other participant had worked in the first work round $(1=$ not hard at all, $7=$ very hard). After they had answered these questions, participants were told that the second work round was cancelled. After this, they were thoroughly debriefed, were asked not to inform other potential participants about the experiment, and were paid and thanked for their participation.

\section{Results}

\section{Manipulation Checks}

By means of the manipulation of decision type we tried to establish that participants were confronted with a relatively important or unimportant decision. A $2 \times 2$ ANOVA on the manipulation check of decision type yielded only a main effect of type of decision, $F(1,118)=21.00, p<0.001$. As intended, participants in the decision about self condition judged the decision to be relatively more important $(M=3.5, S D=2.0)$ than participants in the decision about the other participant condition $(M=2.1$, $S D=1.4)$. It can be concluded that the decision type manipulation was induced as intended.

A $2 \times 2$ MANOVA on the two manipulation checks of procedure (voice and no voice) yielded only a main effect of procedure at both the multivariate level and the univariate levels: multivariate 
$F(2,117)=40.15, p<0.001$; for the voice check $F(1,118)=63.88, p<0.001$; for the no-voice check $F(1,118)=72.22, p<0.001$. These findings show that participants in the voice condition agreed more with the statement that they had been given an opportunity to voice their opinion $(M=5.7 ; S D=1.7)$ than participants in the no-voice condition $(M=2.8 ; S D=2.2)$, and that participants in the no-voice condition agreed more with the statement that they were not given an opportunity to voice their opinion $(M=5.6 ; S D=2.0)$ than participants in the voice condition $(M=2.5 ; S D=1.9)$. This suggests that the procedure manipulation was successfully operationalized.

A $2 \times 2$ ANOVA on participants' answers to what extent they thought the experimenter had paid attention to their opinions yielded only a main effect of procedure, $F(1,118)=60.98, p<0.001$. Participants in the voice condition thought the experimenter had paid more attention to their opinions $(M=4.2 ; S D=1.7)$ than participants in the no-voice condition $(M=2.0 ; S D=1.5)$. This yields corroborative evidence that the manipulation of procedure was induced as intended.

\section{Additional Variables}

Participants' answers to the questions how hard they and the other participant had worked in the first work round were subjected to a 2 (decision type) $\times 2$ (procedure) $\times 2$ (response dimension: own task performance versus other's task performance) MANOVA, with the first two independent variables as between-participants variables and the last independent variable as a within-participants variable. This yielded no significant effects. As expected, participants thought they $(M=5.6 ; S D=1.1)$ and the other participant $(M=5.5 ; S D=1.2)$ had performed their tasks equally well in the first work round.

Participants who were allowed voice $(n=60)$ typed in their opinion about the number of tasks they should perform in the second work round. As expected, a one-way ANOVA yielded no effect of decision type, $F<1$. Independent of decision type, participants thought they should perform the same number of tasks in the second work round $(M=196 ; S D=80.6)$. Thus, these findings show that the manipulation of decision type had no unintended effects on participants' perceptions of their own and the other participants' performance in the first work round and on their voiced opinions.

\section{Dependent Variables}

The means and standard deviations of the dependent variables of Experiment 2 are displayed in Table 2. To analyse the data we conducted a $2 \times 2$ MANOVA on the three scales (procedural justice judgements, procedural affect perceptions, and relational judgements). This MANOVA yielded main effects of procedure at the multivariate level and the univariate levels: multivariate $F(3,116)=12.67$, $p<0.001$; for procedural justice judgements, $F(1,118)=15.64, p<0.001$; for perceived procedural affect, $F(1,188)=28.40, p<0.001$; for relational judgements, $F(1,118)=26.13, p<0.001$. Main effects of decision type were significant at the multivariate level and one univariate level (for relational judgements): multivariate $F(3,116)=5.07, p<0.01$; for relational judgements, $F(1,118)=10.50$, $p<0.01$. More important, the predicted interaction effects were found at the multivariate level and all univariate levels: multivariate $F(3,116)=6.54, p<0.001$; for procedural justice judgements, $F(1,118)=13.13, p<0.001$; for perceived procedural affect, $F(1,118)=8.02, p<0.01$; for relational judgements, $F(1,118)=16.16, p<0.001$.

The results show that, as predicted by Hypothesis 1, participants in the decision about self condition judged the procedure to be more just when they were given an opportunity to voice their opinion than when they were not given such an opportunity, $t(61)=5.90, p<0.001$. In accordance with Hypothesis 
Table 2. Means and standard deviations of the dependent variables as a function of decision type and procedure (Experiment 2)

\begin{tabular}{llcc}
\hline & & \multicolumn{2}{c}{ Decision } \\
\cline { 3 - 4 } Dependent variable & Procedure & About participant self & About other participant \\
\hline Procedural justice judgements & Voice & $\mathbf{5 . 0}(1.2)$ & $\mathbf{4 . 0}(1.6)$ \\
& No voice & $\mathbf{3 . 1}(1.3)$ & $\mathbf{3 . 9}(1.4)$ \\
Perceived procedural affect & Voice & $\mathbf{4 . 9}(0.9)$ & $\mathbf{4 . 5}(0.9)$ \\
& No voice & $\mathbf{3 . 4}(1.1)$ & $\mathbf{4 . 0}(1.1)$ \\
Relational judgements & Voice & $\mathbf{5 . 1}(1.0)$ & $\mathbf{5 . 0}(1.0)$ \\
& No voice & $\mathbf{3 . 4}(1.1)$ & $\mathbf{4 . 8}(1.0)$
\end{tabular}

Note: Entries in bold are means on 7-point Likert-type scales with higher values indicating more positive ratings of the dependent variable in question, and entries within parentheses are standard deviations.

2a, procedural justice judgements in the decision about the other participant condition did not differ as a function of procedure, $t(57)=0.21$, n.s.

In accordance with Hypothesis 1, it was found that participants in the decision about self condition showed more positive affect towards the procedure when they were given an opportunity to voice their opinion than when they were not given such an opportunity, $t(61)=5.90, p<0.001$. In correspondence with Hypothesis 2a, the results did not show a difference in perceived procedural affect between the voice and the no-voice conditions in the decision about the other participant condition, $t(57)=1.73$, n.s.

The relational judgements showed further evidence for our predictions: In the decision about self condition, participants indicated more positive relational judgements when they were given an opportunity to voice their opinion than when they were given no such opportunity, $t(61)=6.32$, $p<0.001$. In the decision about the other participant condition, participants' relational judgements did not differ as a function of procedure, $t(57)=0.79$, n.s.

\section{Discussion}

The results of Experiment 2 corroborate and extend the findings of Experiment 1. Findings of Experiment 2 show that when people are confronted with decisions they judge to be relatively important they are affected by variations in voice. People's perceptions of procedural justice and affect and their judgements about the quality of their relationship with authorities are more positive when people are allowed as opposed to denied an opportunity to voice their opinion about such decisions. However, when people are faced with decisions that are relatively unimportant to them they are not strongly affected by variations in voice. In fact, in Experiment 2, procedural justice perceptions, affect, and relational judgements of participants who received voice about such a decision were not statistically significant from those who were not allowed voice. These findings suggest that relative importance is a significant element of the moderating effect that appropriateness of decisions can have on the voice effect.

In Experiment 2, we successfully created a decision condition (the decision about self condition) that - as suggested by our manipulation check findings - was relatively important to our participants and - as shown by our dependent variables results - was successful in yielding significant voice effects. Furthermore, we were successful in setting up a condition (the decision about other condition) that was judged to be unimportant and that showed an absence of voice effects. Thus, in correspondence with our line of reasoning, we showed that when voice is allowed about unimportant 
decisions, voice effects should not be expected. In everyday life, decision makers do not ask themselves whether they allow voice about decisions that are unimportant or not. Our findings suggest, however, that if we really want to treat people in an honest way, it is essential to make a careful distinction between decisions that are important to people and those that are not.

\section{GENERAL DISCUSSION}

Whereas in Experiment 1 we found evidence for a reversal of the voice effect (on participants' furiousness perceptions), in Experiment 2 no evidence obtained for such a reversal effect. ${ }^{4}$ All dependent variables in Experiment 2 showed the same ordinal interaction effects, yielding evidence for Hypotheses 1 and 2a, but not for Hypothesis 2b. Series of experiments often yield somewhat conflicting results and - unfortunately - the series that we presented here is no exception to this. The fact that we obtained more ordinal patterns (stronger voice effects vs. weaker voice effects) than disordinal patterns (voice effects versus reversal effects) is in correspondence with previous justice experiments in which ordinal interactions have been found more frequently (e.g. Brockner, Heuer, Siegel, Weisenfeld, Martin, Grover, Reed \& Bjorgvinsson, 1998; Van den Bos, 2001; Van den Bos \& Lind, 1999; Van den Bos, Lind, Vermunt \& Wilke, 1997; Van den Bos, Wilke \& Lind, 1998a; Van den Bos, Wilke, Lind \& Vermunt, 1998b) than disordinal interactions (e.g. Folger, 1977; Van den Bos et al., 1996). We can only hope that our differential findings may stimulate future research, but we think it is safe to conclude that our findings show new and important insights into the psychology of voice.

Two important moderators that have been shown in previous studies to lead to reversals of the voice effect are described in Folger (1977) and Van den Bos et al. (1996). Folger's (1977) research shows that when voice procedures are repeatedly followed by unfavourable outcomes, people may become frustrated about their voice opportunities, and hence react more negatively to voice procedures than to no-voice procedures. Van den Bos et al. (1996) have emphasized the importance of people's expectations. When people explicitly are expecting a procedure that will give them no voice opportunity, they may judge the procedure they actually receive to be less fair when this latter procedure is a voice procedure as opposed to a no-voice procedure. These and potential other moderators can weaken the positive effects voice procedures typically have and they can even lead to reversed effects. The great impact of these moderators makes them very important and exciting to study. Studies about potential moderators are for that reason very useful and may substantially further our insights into the psychology of procedural justice.

Another moderator study that should be discussed here is the fifth study by Brockner et al. (1998). These authors found that people who were induced to believe that they were highly capable of providing meaningful input, were more satisfied with their outcome when they were allowed rather than denied voice. In contrast, outcome satisfaction in the lower capability condition was unaffected by variations of voice. This shows that voice strongly affects people when they believe they can provide meaningful input. We suggest here that a similar effect exists for appropriateness of decisions. When the decision is inappropriate for people, they can not provide meaningful input, and for that reason voice may affect them differently than when decisions are appropriate. On the basis of the Brockner et al. findings, we argue here that when someone is allowed an opportunity to voice his or her opinion about an appropriate decision, he or she probably has meaningful things to say about this

\footnotetext{
${ }^{4}$ Even when participants' furiousness perceptions (or other dependent variables) were treated separately in the analyses, no reversal effects were found in Experiment 2.
} 
decision because the decision involves his or her interests, and as a result may react more positive following a voice as opposed to a no-voice procedure. However, not being allowed a voice about an inappropriate decision, about which the person may not feel that he or she has something meaningful to say, may have less effects on the person, and hence the opportunity to voice an opinion may not lead to increased judgements or even may lead to lower judgements as compared with not being allowed voice. Future research may want to investigate this implication.

We would like to point out here that although Experiment 2 suggests that relative importance is crucial in the psychology of people's reactions to appropriate and inappropriate decisions, other psychological mechanisms may be important as well. One mechanism that we would like to discuss here focuses on availability of information. When people possess information and knowledge about a decision, they will appreciate voice about this decision because they have something meaningful to say about it (cf. Brockner et al., 1998). It may be argued that, because they typically possess valuable information about appropriate decisions, participants will feel they have something meaningful to say about appropriate decisions. However, when people get a voice about a decision about which they do not have important information, it may be very difficult for them to express their opinions about such decisions. What we have referred to as inappropriate decisions may be an instance of such decisions, and voice versus no voice about inappropriate decisions hence may not strongly affect people's judgements because they do not have enough knowledge about these kinds of decisions to form an opinion. This line of reasoning suggests that people especially appreciate voice when they know enough about the decision issue to form a meaningful opinion. The findings of the experiment by Brockner et al. (1998) which we discussed earlier show evidence for this assumption. Their findings suggest that people are only affected by voice when they believe that they can provide a meaningful input (cf. Tyler, 1987).

Other possible mechanisms focus on someone's responsibility for and competence about decisions. These mechanisms make the assumption that voice leads to higher fairness judgements when the decision about which voice is allowed belongs to someone's responsibility or competence. Appropriate decisions belong to people's responsibilities and competence whereas inappropriate decisions typically do not. Being allowed a voice about appropriate decisions can perceived to be more fair than not being allowed a voice because appropriate decisions are part of one's duty and competence. Inappropriate decisions, however, may not belong to someone's role responsibility or competence. In Experiment 1, for example, being allowed a voice about how to conduct good psychological research does not belong to the responsibility and competence of the participant; these kinds of decisions should and can be made by the experimenter. Being allowed a voice about such an inappropriate decision does not make the perceived procedure to be more fair and just because the issue and the outcome of the decision are not part of the duty and competence of the participant. We hope that the research findings presented in the current paper will stimulate future research to explore these and other possible mechanisms.

It should be emphasized here that we reasoned that it made sense to perform experimental studies with which we could achieve high internal validity and experimental control. In our studies, we tried to achieve acceptable levels of external validity. One way we tried to do this was to use stimulus materials that had real-life characteristics for our participants (and debriefing interviews indicated that we were successful in this). It should be noted here, however, that care must be taken, of course, to generalize from the experimental findings presented in the current paper to real-world settings. Although we are convinced that our analysis of the psychology of voice is generalizable to other social contexts and experimental manipulations, future research may want to explore the boundary conditions of the effects reported here. However, what matters most is that the present experiments suggest that particular effects may occur. This may stimulate future research to explore other conceptions and operationalizations of what we have presented here. 
But, to return to the concept that motivated the research we report here, the present findings tell us something that is fundamental with regard to the psychology of voice, and they may serve as a startingpoint for a future avenue of research on voice procedures in particular and procedural justice in general. More generally, when Locke and Schweiger concluded in 1979 that participation can have both positive and negative consequences for organizations and their members, they seemed quite dissatisfied with the research literature on PDM and they proposed that the mechanisms which determine the effects of PDM should be investigated. By demonstrating the influence of appropriateness of decisions on procedural judgements and other reactions, the experiments presented in this paper suggest a mechanism that may help in accounting for the positive and negative effects of participation. To be sure, previous studies have shown moderating effects on people's reactions to voice procedures (e.g. Folger, 1977; Peterson, 1999; Tyler, 1987; Van den Bos et al., 1996), but the present paper is the first to reveal that it is important to ask whether participation in decision making is appropriate or inappropriate. One of the reasons why this is important is that, in everyday life, decision makers typically do not distinguish between appropriate and inappropriate decisions. We hope that the current paper may lead scientists and practioners to carefully distinguish between decisions about which being allowed voice is appropriate and those about which it is inappropriate.

\section{ACKNOWLEDGEMENTS}

The research reported in this paper was supported by a fellowship of the Royal Netherlands Academy of Arts and Sciences awarded to Kees van den Bos. We thank Carsten de Dreu, Allan Lind, Charles Stangor, Fritz Strack, Paul van Lange, and the anonymous reviewers for their comments on previous versions of this article; and Anne Kroezen for her help with Experiment 2.

\section{REFERENCES}

Brockner J, Heuer L, Siegel PA, Wiesenfeld B, Martin C, Grover S, Reed T, Bjorgvinsson S. 1998. The moderating effect of self-esteem in reaction to voice: Converging evidence from five studies. Journal of Personality and Social Psychology 75: 394-407.

Dachler HP, Wilpert B. 1978. Conceptual dimensions and boundaries of participation in organizations: A critical evaluation. Administrative Science Quarterly 23: 1-39.

DIO International Research Team. 1983. A contingency model of participative decision making: An analysis of 56 decisions in three Dutch organizations. Journal of Occupational Psychology 56: 1-18.

Earley PC, Lind EA. 1987. Procedural justice and participation in task selection: The role of control in mediating justice judgements. Journal of Personality and Social Psychology 52: 1148-1160.

Folger R. 1977. Distributive and procedural justice: Combined impact of "voice" and improvement on experienced inequity. Journal of Personality and Social Psychology 35: 108-119.

Lind EA, Kanfer R, Earley PC. 1990. Voice, control, and procedural justice: Instrumental and noninstrumental concerns in fairness judgements. Journal of Personality and Social Psychology 59: 952-959.

Lind EA, Tyler TR. 1988. The Social Psychology of Procedural Justice. Plenum: New York.

Locke EA, Schweiger DM. 1979. Participation in decision-making: One more look. Organizational Behavior 1: 265-339.

Peterson RS. 1999. Can you have too much of a good thing? The limits of voice for improving satisfaction with leaders. Personality and Social Psychology Bulletin 25: 313-324.

Sagie A, Elizur D, Koslowsky M. 1989. Effect of participation in strategic and tactical decisions on acceptance of planned change. The Journal of Social Psychology 130: 459-465.

Sagie A, Elizur D, Koslowsky M. 1995. Decision type, participative decision making (PDM), and organizational behavior: An experimental simulation. Human Performance 8: 81-94. 
Strauss G. 1992. Workers' participation in management. Employment Relations. Blackwell: Oxford.

Thibaut J, Walker L. 1975. Procedural Justice: A psychological analysis. Erlbaum: Hillsdale, NJ.

Tyler TR. 1987. Conditions leading to value-expressive effects in judgement of procedural justice: A test of four models. Journal of Personality and Social Psychology 52: 333-344.

Tyler TR, Lind EA. 1992. A relational model of authority in groups. In Advances in Experimental Social Psychology (Vol. 25), Zanna M (ed.). Academic Press: San Diego, CA; 115-191.

Tyler TR, Smith HJ. 1998. Social justice and social movements. In The Handbook of Social Psychology, Gilbert DT, Fiske ST, Lindzey G (eds). Oxford University Press: New York; 595-639.

Van den Bos K. 2001. Uncertainty management: The influence of uncertainty salience on reactions to perceived procedural fairness. Journal of Personality and Social Psychology 80: 931-941.

Van den Bos K, Bruins J, Wilke HAM, Dronkert E. 1999. Sometimes unfair procedures have nice aspects: On the psychology of the fair process effect. Journal of Personality and Social Psychology 77: 324-366.

Van den Bos K, Lind EA, Vermunt R, Wilke HAM. 1997. How do I judge my outcome when I do not know the outcome of others?: The psychology of the fair process effect. Journal of Personality and Social Psychology 72 : 1034-1046.

Van den Bos K, Vermunt R, Wilke HAM. 1996. The consistency rule and the voice effect: The influence of expectations on procedural fairness judgements and performance. European Journal of Social Psychology 26: 411-428.

Van den Bos K, Wilke HAM, Lind EA. 1998. When do we need procedural fairness? The role of trust in authority. Journal of Personality and Social Psychology 75: 1449-1458.

Van den Bos K, Wilke HAM, Lind EA, Vermunt R. 1998. Evaluating outcomes by means of the fair process effect: Evidence for different processes in fairness and satisfaction judgments. Journal of Personality and Social Psychology 74: 1493-1503.

Vermunt R, Wit AP, Van den Bos K, Lind EA. 1996. The effects of unfair procedure on affect and protest. Social Justice Research 9: 109-119.

Watson D, Clark LA, Tellegen A. 1988. Development and validation of brief measures of positive and negative affect: The PANAS scales. Journal of Personality and Social Psychology 54: 1063-1070. 